\title{
ESQUEMA ESTATÍSTICO DE COMBINAÇÃO E CORREÇÃO DE PREVISÕES CLIMÁTICAS - ECCOCLIM
}

\author{
ANA CLEIDE N. BEZERRA ${ }^{1}$, LUCIANO P. PEZZI² E MARY T. KAYANO ${ }^{2}$ \\ ${ }^{1}$ Sistema de Proteção da Amazônia (SIPAM), Centro Técnico e Operacional de Manaus (CTO/Mn) \\ ${ }^{2}$ Instituto Nacional de Pesquisas Espaciais, Centro de Previsão de Tempo e Estudos Climáticos \\ (INPE/CPTEC) \\ ana.bezerra@sipam.gov.br
}

Recebido Junho 2007 - Aceito Fevereiro 2008

\begin{abstract}
RESUMO
Uma técnica de pós-processamento é aplicada para corrigir estatisticamente, as previsões de precipitação geradas pelos modelos climáticos numéricos disponíveis no CPTEC. O método chamado de Esquema Estatístico de Combinação e Correção de Previsões Climáticas (ECCOCLIM) é determinístico e baseia-se no método de Regressão Linear Múltipla (RLM). A verificação do desempenho é feita com a técnica de validação cruzada. Apesar dos ganhos observados nas previsões com o novo método serem localizados e variados ao longo dos anos, estes são destacados em áreas da América do Sul, as quais usualmente apresentam baixa previsibilidade climática, como no caso das regiões Sudeste e Centro-Oeste. Em geral, sobre a América do Sul o ECCOCLIM mostra resultados melhores, reduzindo os erros, comparados à tradicional média aritmética das previsões de diferentes modelos.
\end{abstract}

Palavras-Chave: Previsão Climática, Super-conjunto de Multi-modelos, ECCOCLIM

\begin{abstract}
CLIMATE FORECAST COMBININGAND CORRECTING STATISTICAL SCHEME - ECCOCLIM.

A post-processing technique is applied to statistically correct the rainfall forecasts done by numerical climate models available at CPTEC. The statistical algorithm, called Climate Forecast Combining and Correcting Statistical Scheme (ECCOCLIM), is deterministic and based on the Linear Multiple Regression (LMR) method. The skill of the ECCOCLIM is verified with the cross-validation method. Although the forecast improvements using the new method are localized in certain regions and vary throughout the year, they are remarkable over South America, mainly in those areas where climatic previsibility is commonly low as the case of Southeast and Central-West regions. ECCOCLIM shows encouraging results over South America reducing the errors when compared to the traditional arithmetic mean of forecasts of different models.
\end{abstract}

Palavras-Chave: Climate Forecast, Multimodel Superensemble, ECCOCLIM

\section{INTRODUÇ̃̃̃O}

As condições de tempo e clima afetam diretamente diversas atividades humanas. Assim, o planejamento de atividades, como a agricultura, energia, recursos hídricos, leva à necessidade de se ter previsões confiáveis das condições de tempo e clima. Desta forma, tem sido constante a preocupação dos cientistas em melhorar as previsões de tempo e clima, o que tem levado à elaboração de técnicas para se chegar a um produto final satisfatório. Uma técnica bastante usada é chamada previsão por conjuntos e tem por base o estudo de Lorenz (1963) que examinou as incertezas do estado inicial em um sistema não linear. Esta técnica consiste em se obter a média de múltiplas integrações (membros) usando um mesmo modelo, mas com condições iniciais ligeiramente diferentes. Neste contexto, vários autores têm mostrado que previsões por conjuntos são estatisticamente mais consistentes com as observações do que a previsão de um modelo individual. Danard et al. (1968) e Thompson (1977) décadas atrás mostravam que o erro médio quadrático (RMSE) de previsões construídas para uma combinação de dois previsores é menor do que o de uma previsão individual. Gneiting e Raftery (2005), apresentando uma discussão sobre o potencial das previsões por conjuntos, ressaltaram a importância em se fazer um pós-processamento 
estatístico das saídas dos modelos. Um dos grandes avanços neste sentido foi estender a técnica de previsão por conjuntos pelo uso de conjuntos de integrações com diferentes modelos, ou com configurações (parametrizações físicas) diferentes. Esta técnica é chamada previsão por superconjuntos de multimodelos. A idéia é a de se extrair de forma objetiva o melhor de cada modelo dinâmico, utilizando análises estatísticas para combinar e corrigir as previsões.

Apesar do grande avanço para se melhorar a previsão do tempo e clima, algumas regiões apresentam baixa previsibilidade climática, como é o caso da previsão climática para o sudeste do Brasil. Isso se deve possivelmente pelo fato de que o clima desta região não tem um sinal claro de variabilidade interanual associada ao El Niño/Oscilação Sul, como é o caso de outras regiões da América do Sul como o Norte/Nordeste e Sul (Ropelewski e Halpert 1987, 1989). No caso das regiões Norte e Nordeste do Brasil (NEB), vários estudos têm demonstrado que a precipitação tem também um forte acoplamento com as variações de temperatura da superfície do mar (TSM) do Atlântico tropical (Moura e Shukla, 1981; Pezzi e Cavalcanti, 2001; Kayano e Andreoli, 2006).

Nas regiões onde existe um forte acoplamento entre variabilidade climática e TSM dos oceanos tropical, como nas regiões Sul e NEB, a previsibilidade climática é melhor do que no sudeste do Brasil. De fato, as previsões climáticas por conjunto, realizadas atualmente com modelos dinâmicos para a região Sudeste do Brasil, apresentam uma baixa previsibilidade climática. Portanto, as diversas áreas da América do Sul apresentam-se heterogêneas em termos de previsibilidade climática, mesmo quando se utiliza a previsão por conjuntos.

$\mathrm{Na}$ tentativa de melhorar a previsão por conjuntos, Krishnamurti et al. (1999; 2000a; 2000b; 2001) propuseram uma técnica chamada de superconjunto de multimodelos que consiste em um método poderoso de pós-processamento capaz de corrigir estatisticamente as previsões geradas pelos modelos numéricos. Atualmente este é um método promissor para se melhorar as previsões sazonais climáticas.

O objetivo do presente trabalho é apresentar e avaliar o uso da técnica de superconjunto de multimodelos sugerido por Krishnamurti et al. (1999; 2000a; 2000b; 2001) para a correção estatística das previsões climáticas de precipitação sobre a América do Sul, geradas pelos modelos numéricos climáticos do CPTEC (Cavalcanti et al., 2002). Aqui, este método é chamado de Esquema Estatístico de Combinação e Correção de Previsões Climáticas (ECCOCLIM).

\section{MATERIAIS E MÉTODO}

\section{1 - Metodologia}

Numa série de artigos, Krishnamurti et al. (1999; 2000a; 2000b; 2001) descreveram a técnica e detalharam suas aplicações para previsões de tempo e clima. Eles mostraram que as previsões geradas por superconjunto, usando pesos estatísticos diferenciados para cada membro e que também variam no espaço, apresentam desempenhos superiores em relação às previsões feitas tomando-se somente a média aritmética dos membros. O método usado no presente trabalho é ligeiramente distinto do proposto por estes autores, em vista de que foi utilizado o modelo de circulação geral do CPTEC (um único modelo), mas com diferentes parametrizações da convecção profunda tipo cumulus. Estas parametrizações usaram os seguintes esquemas: Kuo (KUO), modificado Arakawa Schubert (RAS) e o Grell (GRELL). Todos estes experimentos foram compostos por 9 integrações (membros) cada.

O ECCOCLIM é determinístico é baseia-se na técnica estatística da Regressão Linear Múltipla (RLM) e inclui duas fases. Na primeira, chamada fase de treinamento é aplicada a RLM para determinação dos pesos estatísticos para as diferentes simulações climáticas e as melhores estimativas da observação. A outra fase é chamada de verificação. $\mathrm{Na}$ primeira fase, determina-se o peso de cada membro que será usado na reconstrução da previsão final que caracteriza o superconjunto.

O ECCOCLIM, escrito em linguagem computacional Fortran 90 (Figura 1), permite que o método seja usado operacionalmente visando o desempenho computacional. Este esquema segue o conceito de software modular, com módulos independentes que usam o conceito de linguagem objeto. Desta forma é possível incluir novas métricas de verificação, ou até mesmo alguma outra metodologia de cálculo dos pesos, bastando apenas incluir uma nova sub-rotina no esquema.

\subsubsection{MÓDULOS DO ESQUEMA}

A Figura 1 mostra o fluxograma com os principais módulos que compõem o ECCOCLIM. No primeiro módulo, Sizes, são encontradas as declarações dos tamanhos das variáveis globais usadas ao longo do código. No módulo Inout, encontram-se as sub-rotinas que fazem a leitura e a escrita dos dados durante o processamento. No módulo Preproc, são calculados os pré-processamentos dos dados, como o cálculo da climatologia, anomalias, desvio padrão e normalização das séries temporais. A RLM é calculada no módulo Mlreglp. No módulo Sensemble, é feito o cálculo da reconstrução da previsão, ou seja, a previsão final baseada em todos os modelos usados na fase de treinamento, porém considerando-se o peso individual de cada um deles de acordo com os coeficientes obtidos pelo módulo Mlreglp. No módulo Metric, são realizados os cálculos da validação da previsão, ou seja, as métricas de avaliação do 


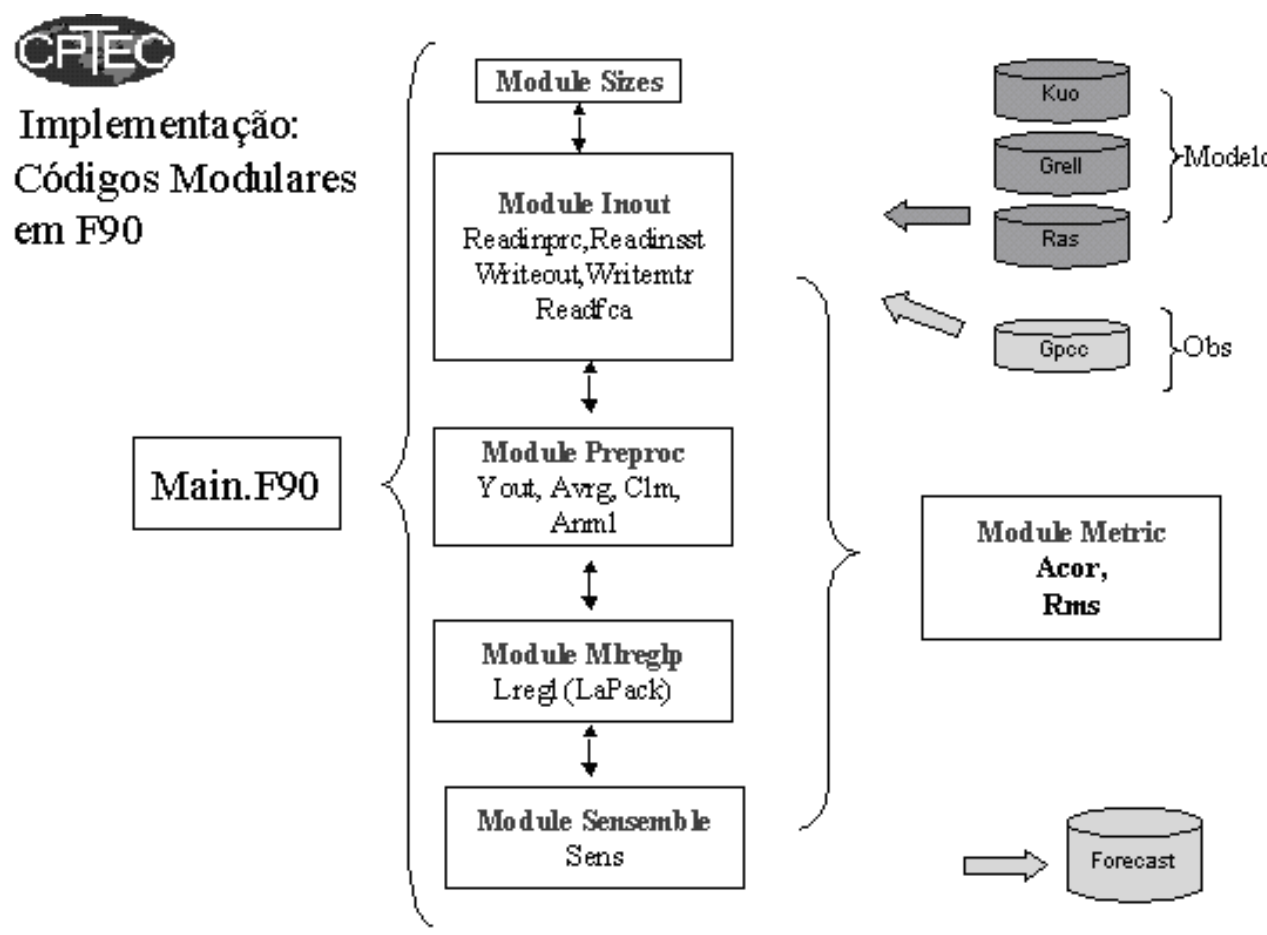

Figura 1 - Fluxograma esquemático do ECCOCLIM mostrando os principais módulos, dados de entradas provenientes das observações e dos diferentes modelos (Pezzi et al., 2006b).

desempenho do ECCOCLIM, tal como o cálculo do RMSE. A verificação da previsão é feita usando-se a técnica de validação cruzada. Neste procedimento, um ano é repetidamente retirado da série original e os coeficientes são estimados com o restante desta série. Posteriormente, a previsão é feita para este ano retirado e validado contra a observação.

\section{2 - Formulação Teórica}

A formulação estatística do método para a criação de um superconjunto de multimodelos (Krishnamurti et al., 2000b) para um dado ponto de grade é mostrada a seguir:

$$
S=\bar{O}+\sum_{i=1}^{N} a_{i}\left(F_{i}-\bar{F}_{i}\right)
$$

onde $\mathrm{S}=$ previsão do superconjunto, $\bar{O}=$ média temporal dos dados observados, $a_{i}=$ pesos para o modelo ${ }_{\mathrm{i}}, \mathrm{N}=$ número de modelos, $\mathrm{F}_{1}=$ média temporal das previsões feita pelo modelo ${ }_{\mathrm{i}}$, $\mathrm{F}_{1}=$ previsão feita pelo modelo ${ }_{\mathrm{i}}$. Os pesos $a_{i}$ são computados para cada ponto de grade e são minimizados pela seguinte função:

$$
G=\sum_{t=0}^{t-\text { trein }}\left(S_{t}-O_{t}\right)^{2}
$$

onde $\mathrm{O}=$ é o estado observado, $\mathrm{t}=$ é o tempo, $\mathrm{t}$-trein $=$ é o comprimento do período de treinamento.

A métrica utilizada para verificar o desempenho das várias previsões é a de avaliar o erro quadrático médio (RMSE) das previsões em relação aos dados observados. A previsão de controle (MEAN) utilizada é a média aritmética simples dos modelos climáticos

\section{3 - Dados}

São usados 20 anos de dados mensais de precipitação, de janeiro de 1982 a dezembro 2001, do Global Precipitation Climatology Centers (GPCC), provenientes do National Centers for Environmental Prediction (NCEP). Este conjunto de dados combina observações de estações de superfície com estimativas derivadas de satélite (Adler et al. 2003).

Os dados de precipitação mensal para caracterizar membros diferentes são obtidos por integrações no modo climático do modelo de circulação global atmosférico (MCGA) do CPTEC na resolução T62L28. Em cada rodada, é usado um esquema diferente de parametrização da convecção cumulus (profunda). Isto caracteriza cada grupo de integração como sendo um modelo diferente do outro. Na primeira rodada é usado 
o esquema Kuo (KUO), na segunda o esquema modificado de Arakawa e Schubert (RAS) e na terceira o esquema de Grell (GRELL). Detalhes sobre os esquemas KUO e RAS podem ser encontrados em Pezzi et al. (2006a). As simulações climáticas foram realizadas em modo de conjunto, com o modelo usando 9 condições iniciais diferentes, derivadas de 9 análises consecutivas do European Centre for Medium-Range Weather Forecasts (ECMWF). As datas iniciais e comprimento das integrações diferem entre cada um dos conjuntos de integração, KUO, RAS e GREEL. Porém, neste estudo foi tomado o período de janeiro de 1982 a dezembro de 2001, pois este período é comum a todos os experimentos. As análises feitas com o ECCOCLIM consideram a média do conjunto de 9 membros de cada experimento. Por exemplo, o conjunto KUO é a média das 9 integrações realizadas usando-se o esquema Kuo. O RMSE é calculado em cada ponto de grade e posteriormente é feita uma média para algumas áreas selecionadas mostradas na Figura 2.

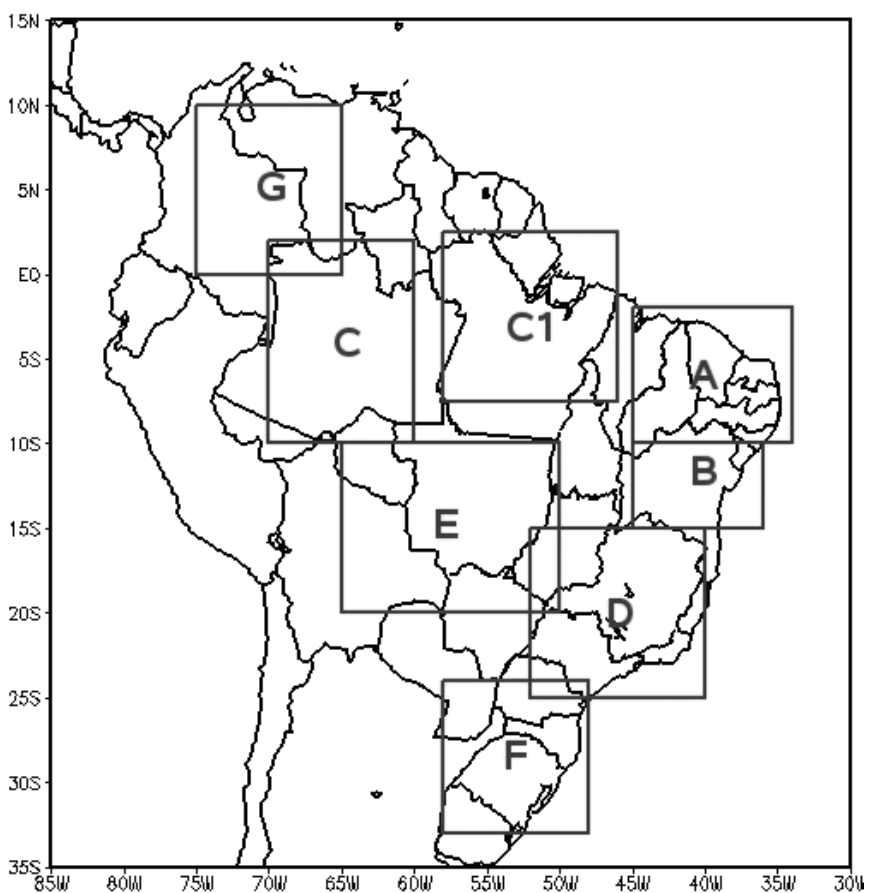

Figura 2 - Áreas testadas com o ECCOCLIM, com as seguintes correspondências: área $\mathrm{A} \leftrightarrow$ norte do $\mathrm{NEB}$, área $\mathrm{B} \leftrightarrow$ sul do $\mathrm{NEB}$, área $\mathrm{C} \leftrightarrow$ oeste da região norte do Brasil; área $\mathrm{C} 1 \leftrightarrow$ leste da região norte do Brasil; área D $\leftrightarrow$ sudeste do Brasil; área $\mathrm{E} \leftrightarrow$ Centro Oeste do Brasil; área $\mathrm{F} \leftrightarrow$ sul do Brasil; e área $\mathrm{G} \leftrightarrow$ noroeste da América do Sul

\section{RESULTADOS E DISCUSSÕES}

\section{1 - Análise dos pesos}

Os pesos estatísticos para cada área são ilustrados na Figura $3 \mathrm{a}-\mathrm{h}$. Para todas as regiões é obervado que a parametrização utilizando o esquema de Kuo apresenta os maiores valores de pesos, em seguida o esquema Ras e valores próximos de zero, utilizando o Grell. Isso pode ser observado durante a estação chuvosa (fevereiro a maio) do Norte do Nordeste (NNEB), onde o esquema de Kuo apresentou valores superiores aos dois outros esquemas. No Sul do Nordeste (SNEB), esse comportamento também foi observado no final da estação chuvosa, assim como, sobre o oeste da Amazônia Legal, no entanto com sinal oposto. Foi observado pequenas variações no período chuvoso (novembro, dezembro, janeiro e fevereiro) das áreas D, E e F, porém as maiores oscilações nos pesos são visualizadas durante os demais meses. $\mathrm{O}$ noroeste da América do Sul (NOAS) também apresentou variações no período chuvoso, porém durante o inverno e inicio da primavera (hemisfério norte) foram observadas variações opostas entre os esquemas Grell e Ras.

\subsection{Análises do RMSE sobre a América do Sul}

A verificação é realizada para oito áreas sobre a América do Sul ilustradas na Figura 2.

A Figura 4 mostra o RMSE sazonal, calculados ponto a ponto, sobre a América do Sul. De um modo geral, a previsão para a América do Sul formada pelo superconjunto de multimodelos apresenta erros menores do que a média, ao longo do ano sobre o noroeste da América do Sul e durante o verão sobre a Cordilheira dos Andes e a região da Zona de Convergência do Atlântico Sul (ZCAS). Alguns estudos sugerem que os erros encontrados sobre as duas primeiras regiões são associados respectivamente a superestimativa de precipitação na região da Zona de Convergência Intertropical (ZCIT) do Pacífico e à deficiência dos modelos em representar bem a orografia (Cavalcanti et al., 2002).

Nas regiões em que os modelos dinâmicos tendem a superestimar a precipitação, o ECCOCLIM tende a corrigir, e apresenta resultados satisfatórios. Porém em algumas áreas, como no caso da região Sul, durante todas as estações, não foi obtido um bom desempenho do método. Essa região é conhecida como de média previsibilidade climática, o que pode ser uma das razões para o fraco desempenho do método. Por outro lado, na pré-estação chuvosa (dezembro, janeiro e fevereiro) e estação chuvosa do sul do NEB (março, abril e maio) observam-se um ganho do método ECCOCLIM comparado à média aritmética. 

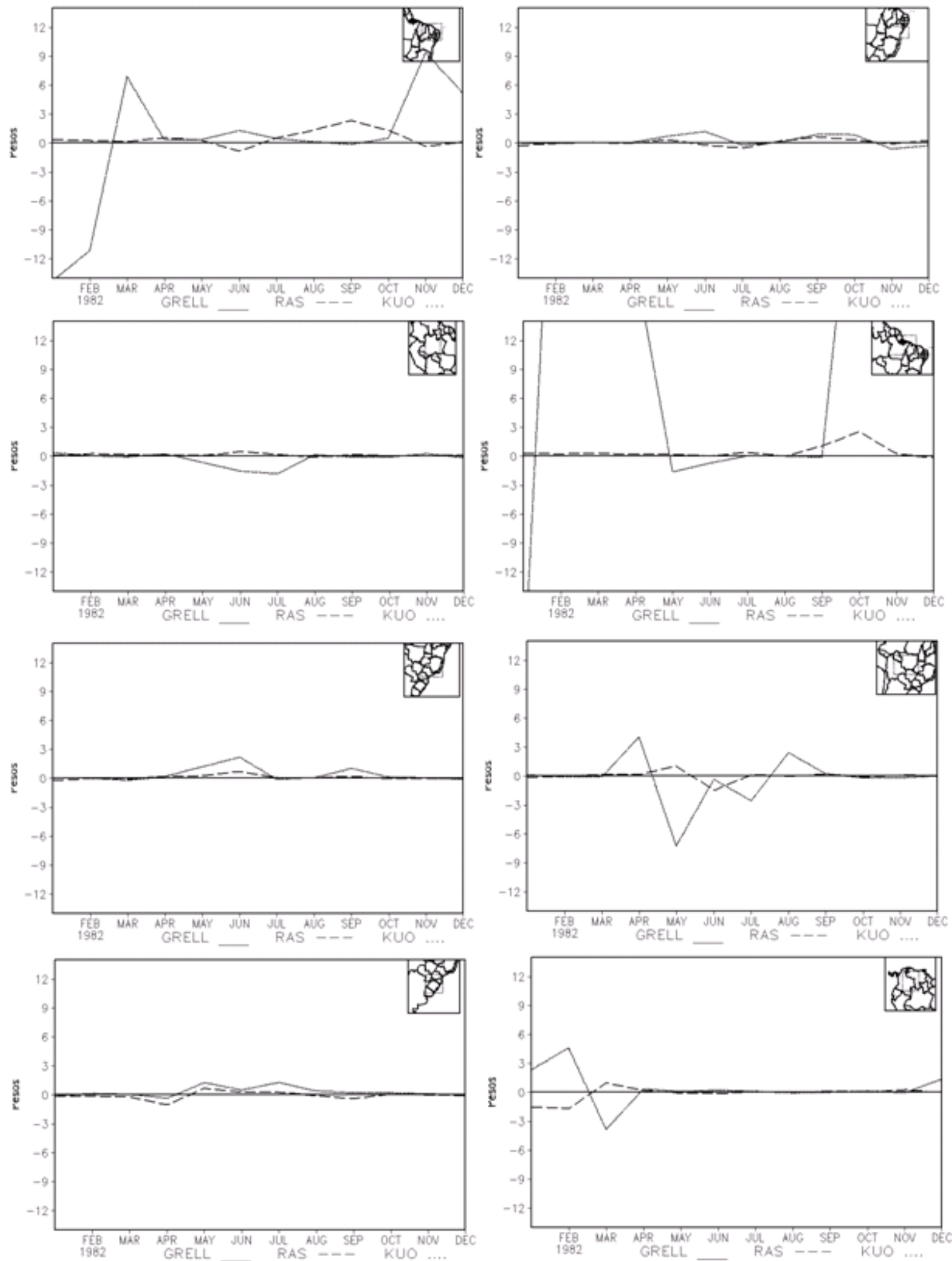

Figura 3 - Peso estatístico médio mensal sobre as áreas ilustradas na Figura 2. 


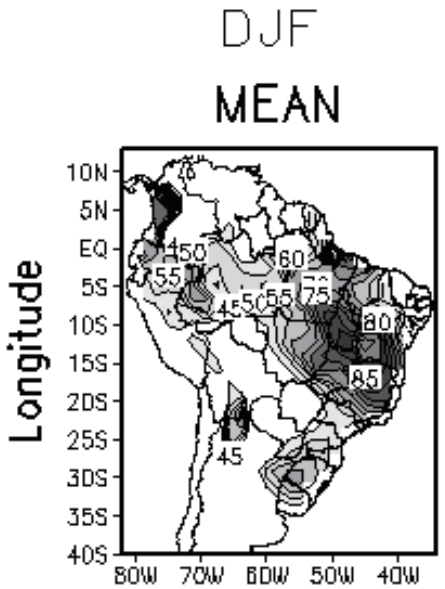

MAM

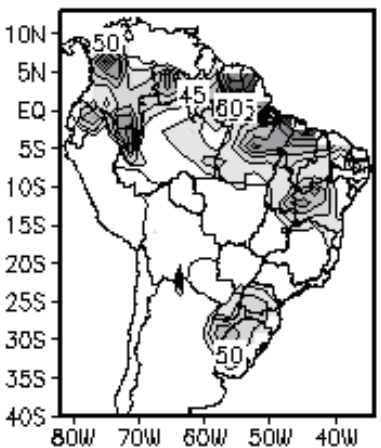

ENSE

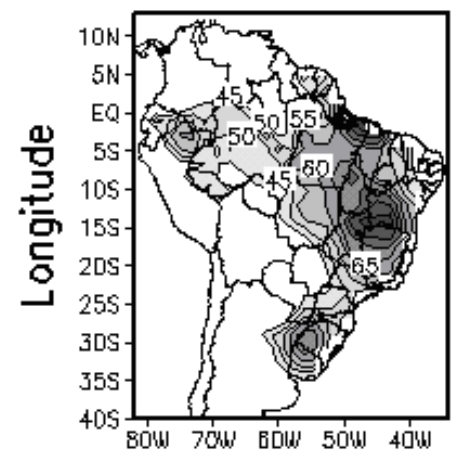

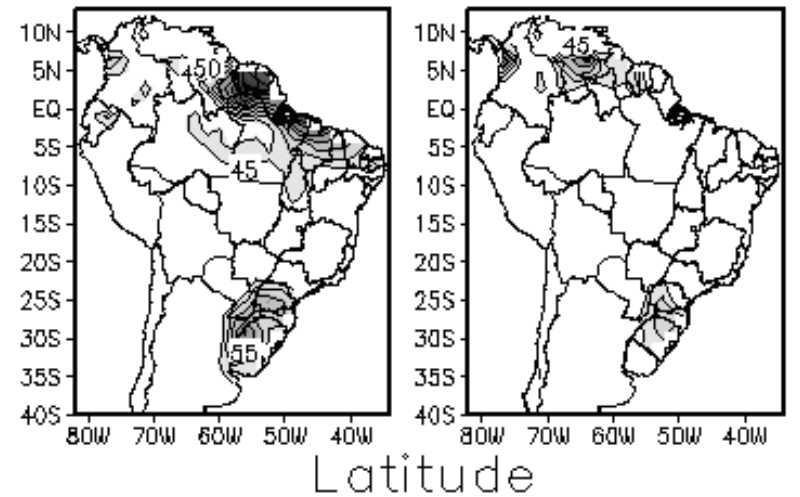

J $\mathrm{A}$
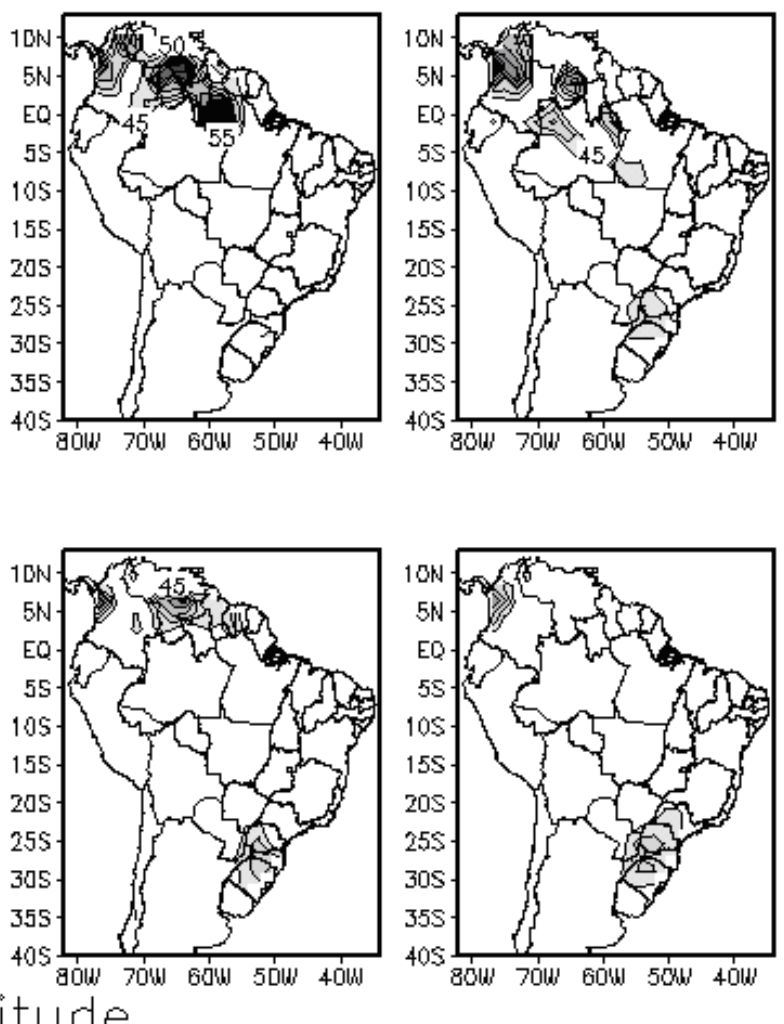

Figura 4 - Mapas sazonais de RMSE sobre a América do Sul para as previsões do ECCOCLIM (ENSE) e da previsão média aritmética dos modelos (MEAN) Unidades em mm/mês.

\section{3 - Avaliação em algumas áreas sobre o Brasil}

As Figuras de 5 a 12 mostram as medidas dos erros nas áreas indicadas na Figura 2 para alguns meses selecionados. Em geral, estes meses correspondem aos mais chuvosos de cada área, segundo Rao e Hada (1990), Hoffmann (1975) e Marengo (1995). Para simplificar a discussão, o RMSEs da previsão corrigida e da previsão media aritmética dos modelos serão referidas respectivamente como ENSE e MEAN.

Sobre a área A, durante a pré-estação chuvosa da região, o método aplicado não apresenta melhoras significativas, apenas em alguns anos os ENSEs são menores do que os MEANs, como em fevereiro. No outono, em abril para vários anos os ENSEs são menores do que os MEANs, enquanto em março e maio as curvas de ENSE e MEAN são quase coincidentes para a maioria dos anos (Figura 5). As curvas de ENSE e de MEAN nos meses de inverno e primavera apresentam RMSE abaixo de $30 \mathrm{~mm} / \mathrm{mês}$ (Figuras não mostradas).

$\mathrm{Na}$ área $\mathrm{B}$ (Figura 6) o ECCOCLIM tem erros grandes durante dezembro e janeiro de alguns anos (Figuras não mostradas). Em fevereiro, os ENSEs são bem menores do que os MEANs (Figura 6). Os RMSE de ambos os métodos são em abril menores do que $90 \mathrm{~mm} / \mathrm{mês}$ e em maio menores do que $62 \mathrm{~mm} /$ mês (Figura 6), e permanecem com valores menores do que $62 \mathrm{~mm} /$ mês até o final da primavera, quando os RMSE apresentam valores acima desse valor (Figuras não mostradas).

A região Norte do Brasil compreende grande parte da maior floresta tropical do planeta e foi dividida em duas áreas (C e C1). Sobre a área C (Figura 7), nos meses de inverno e primavera o ECCOCLIM corrige a previsão com resultados satisfatórios (Figuras não mostradas) com valores de RMSE 

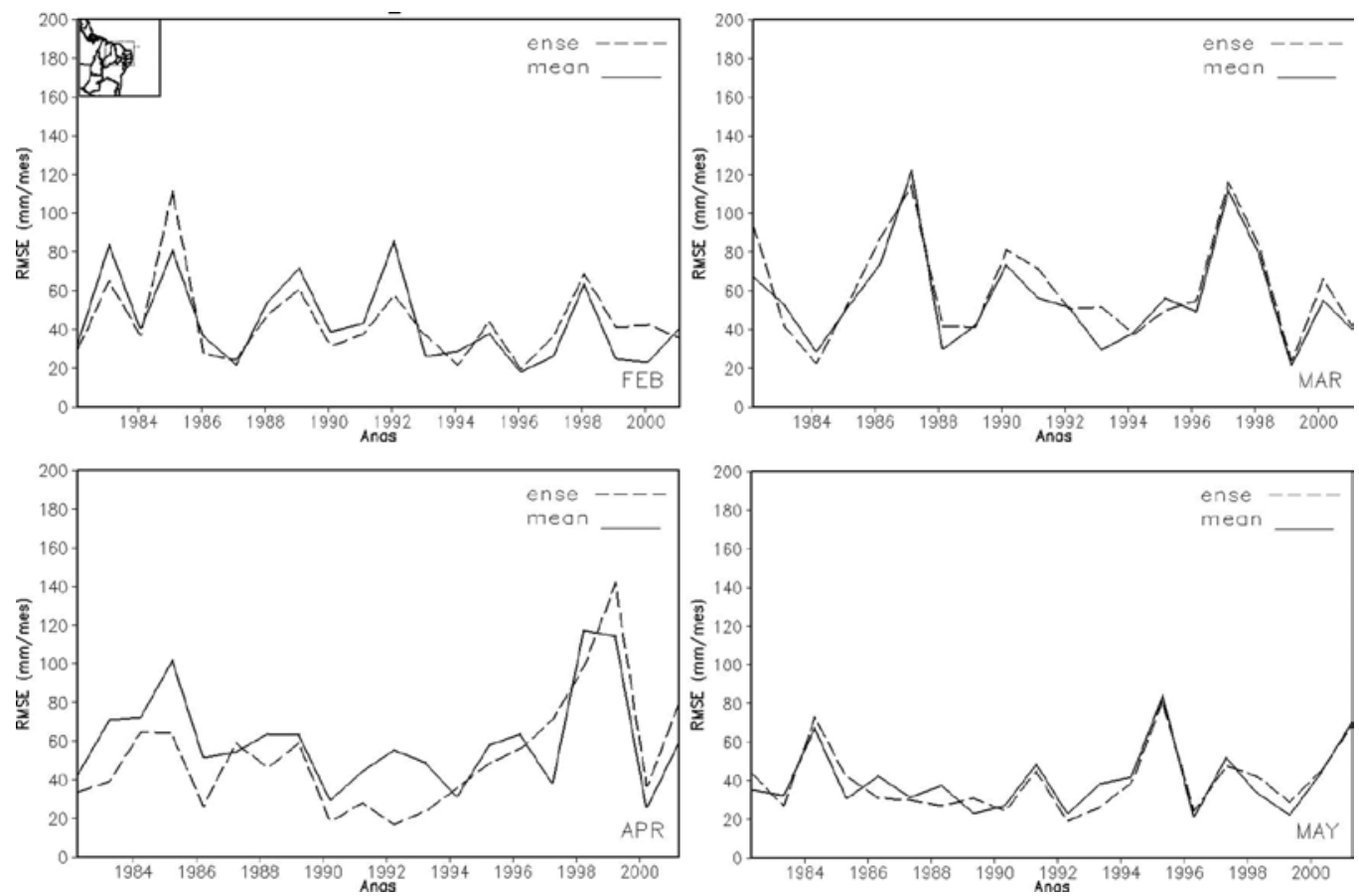

Figura 5 - Média espacial do RMSE mediado sobre a área A da previsão corrigida pelo ECCOCLIM (curva tracejada e indicada por ENSE) e da previsão média aritmética dos modelos (curva continua e indicada por MEAN) para os meses de fevereiro a maio. Unidades em mm/mês durante 1982 a 2001
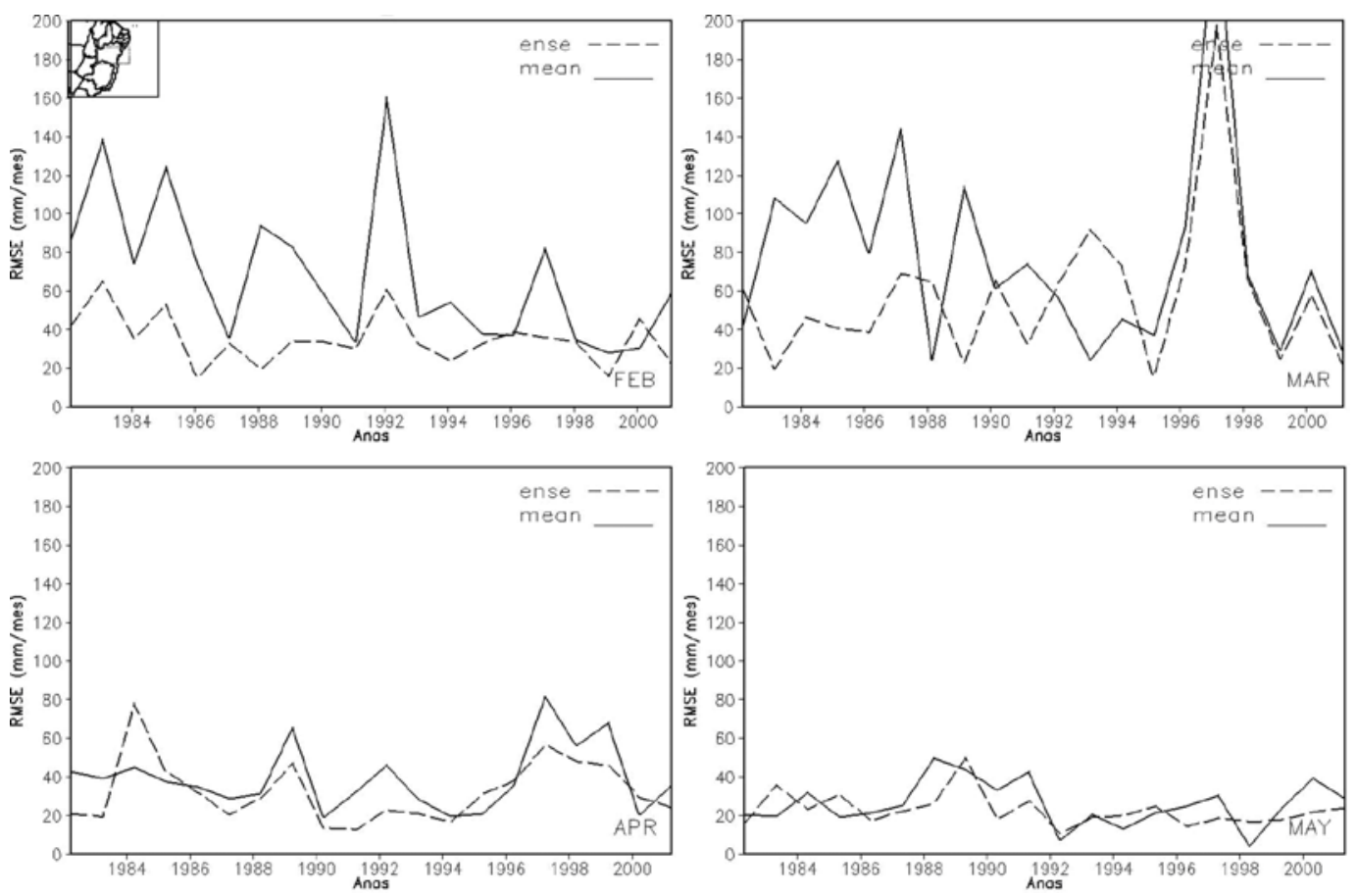

Figura 6 - Idem à Fig. 5, porém para a área B 
mensais abaixo de $40 \mathrm{~mm}$. Nos demais meses da estação de verão e outono, ambos permaneceram dentro do intervalo de 40 a $60 \mathrm{~mm} / \mathrm{mês}$. E vale salientar, que os valores do ENSEs são ligeiramente menores do que os correspondentes MEANs. Apenas para ilustrar os gráficos dos meses de março a junho estão mostrados na Figura 7.

No Leste da Amazônia em janeiro, os dois métodos apresentam valores muito próximos nos meses de janeiro e fevereiro, no entanto altos. Em geral, nos meses de verão (dezembro-janeiro-fevereiro) os ENSEs tornaram-se ligeiramente abaixo dos MEANs, no entanto anos atingido valores acima de $120 \mathrm{~mm} /$ mês (Figuras não mostradas). Em março dos anos de 1982 a 1988 as previsões corrigidas com o esquema ECCOCLIM apresentam resultados satisfatórios, a partir de 1989 os ENSEs permanecem ligeiramente acima dos MEANs (Figura não mostrada). As melhorias das previsões com o ECCOCLIM são notáveis no leste da Amazônia nos meses de maio a outubro (Figura 8), atingindo no mês de setembro rmse valores abaixo de $20 \mathrm{~mm} / \mathrm{mês}$. Na Figura 8 estão ilustrados os gráficos correspondentes aos meses de maio a agosto. No final da primavera os RMSE de ambos os esquemas apresentam valores em torno de $30 \mathrm{~mm} /$ mês (Figuras não mostradas).

A melhoria na utilização do ECCOCLIM encontrada sobre regiões de baixa e/ou média previsibilidade climática (principalmente as de baixa), apesar de poucas e em meses isolados são considerados grandes avanços no desenvolvimento de estudos do tempo e clima. Em áreas consideradas de alta previsibilidade climática, essas poucas melhorias podem não ser tão satisfatórias como sobre as áreas de baixa e média previsibilidade Climática.

Para a região $\mathrm{D}$ (sudeste do Brasil) a utilização do método ECCOCLIM não mostra uma melhoria considerável, como ilustrado para os meses de novembro a fevereiro. Nestes meses, apenas em alguns anos isolados os RMSEs do ECCOCLIM apresentam valores menores do que os correspondentes MEANs (Figura 9). De abril a outubro, os RMSE tanto do ECCOCLIM quanto os da média dos modelos têm valores dentro do intervalo 20 a 40 mm/mês (Figuras não mostradas).

Assim como o Sudeste, o Centro-oeste é uma região de baixa previsibilidade climática. Para esta região a utilização do método ECCOCLIM também não mostra uma melhoria considerável, como ilustrado para os meses de novembro a fevereiro quando o ECCOCLIM mostra apenas alguns anos com erros ligeiramente menores do que os encontrados com a média aritmética dos modelos (Figura 10). De maio a outubro, os RMSE tanto do ECCOCLIM quanto os da média dos modelos comportam-se semelhantes aos da área $\mathrm{D}$, apresentando também valores dentro do intervalo 20 a $40 \mathrm{~mm} / \mathrm{mês}$.

Para o Sul do Brasil (área F), região considerada de média previsibilidade climática, não mostra bons resultados com a aplicação do ECCOCLIM, como ilustrado para os meses de novembro a março (Figura 11).
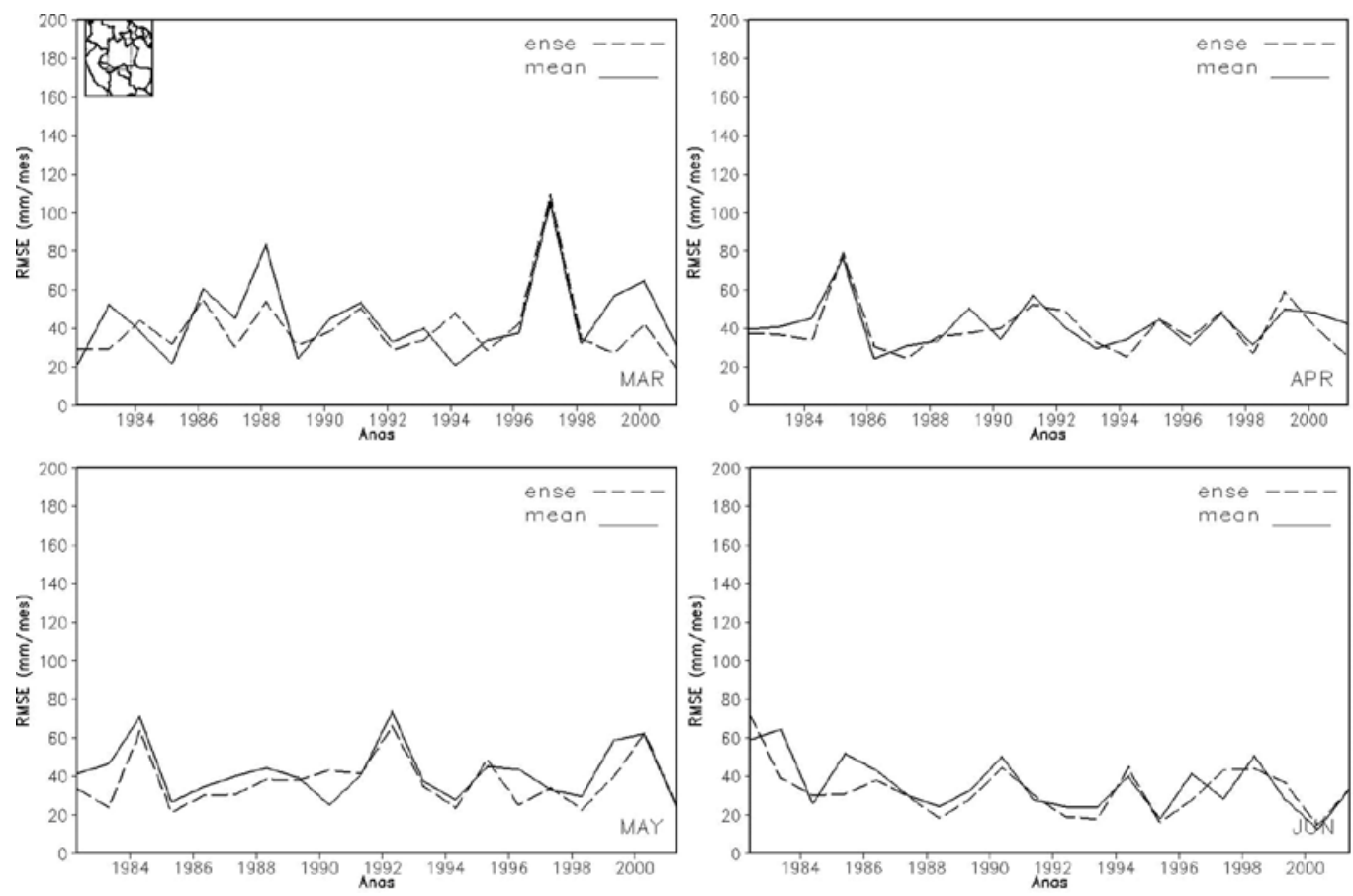

Figura 7 - Idem à Fig. 5, porém para a área $\mathrm{C}$ e para os meses de março a junho 

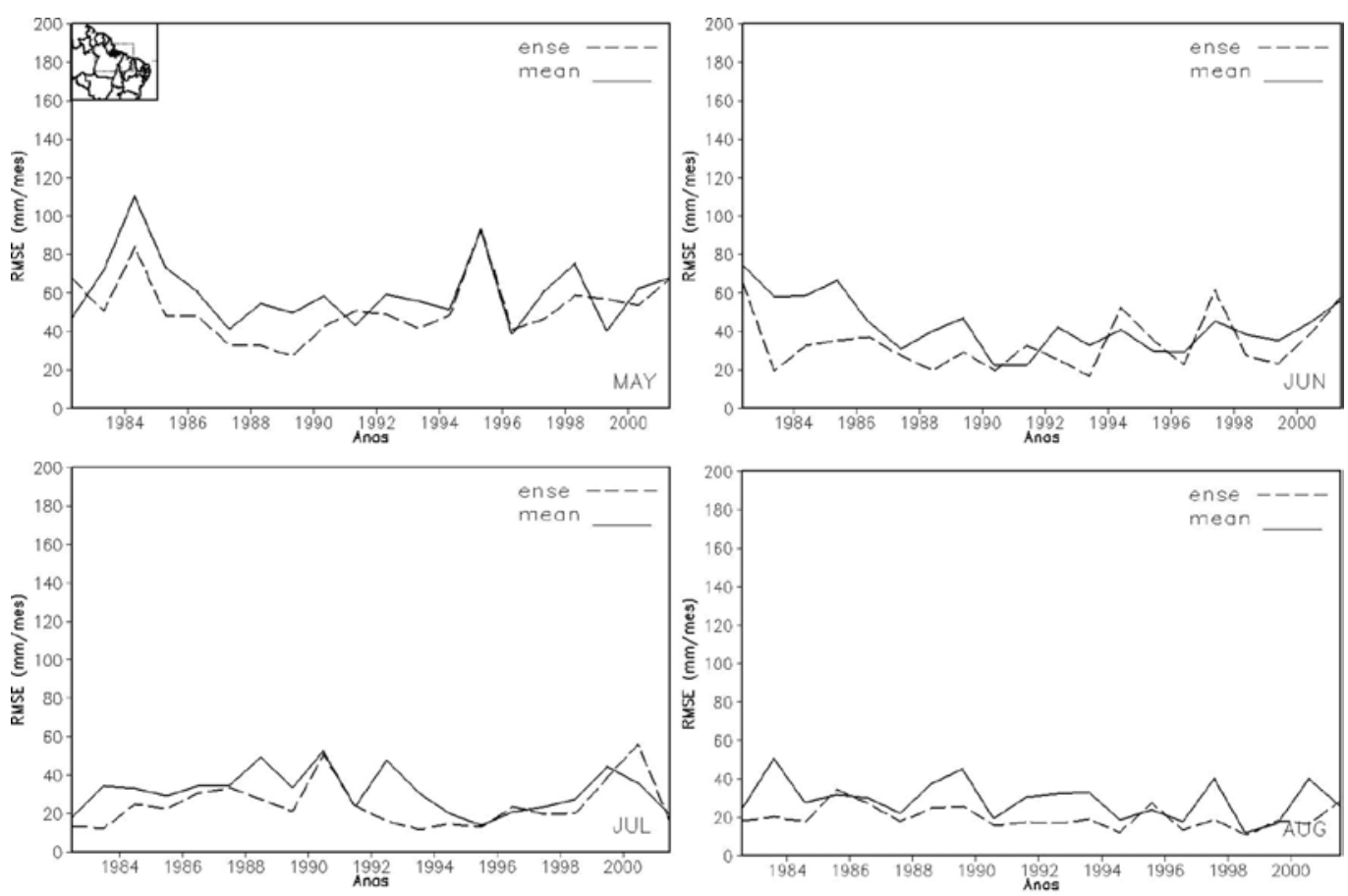

Figura 8 - Idem à Fig. 5, porém para a área $\mathrm{C} 1$ e para os meses de maio a agosto
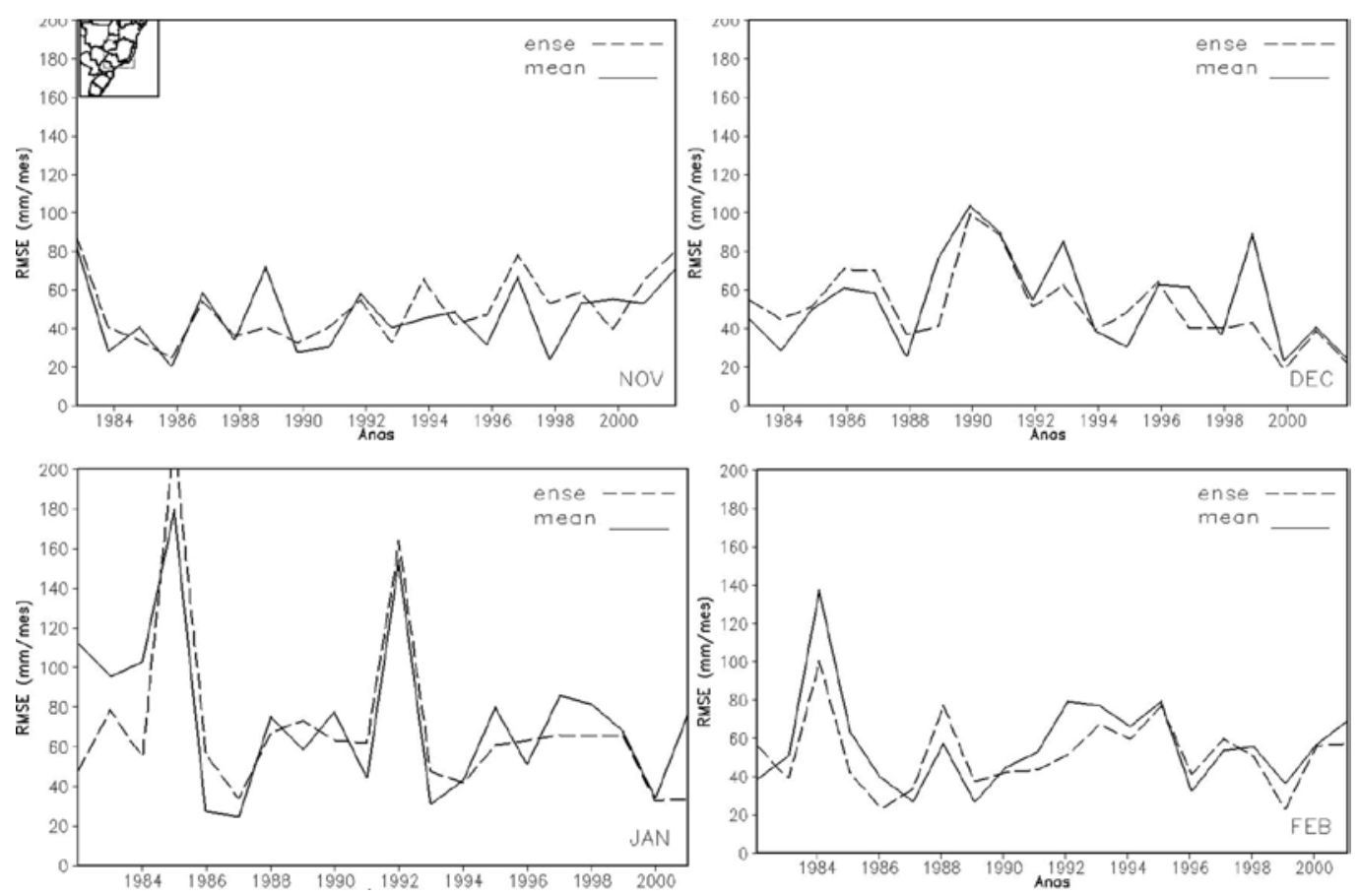

Figura 9 - Idem à Fig. 5, porém para a área D e para os meses de novembro a fevereiro 

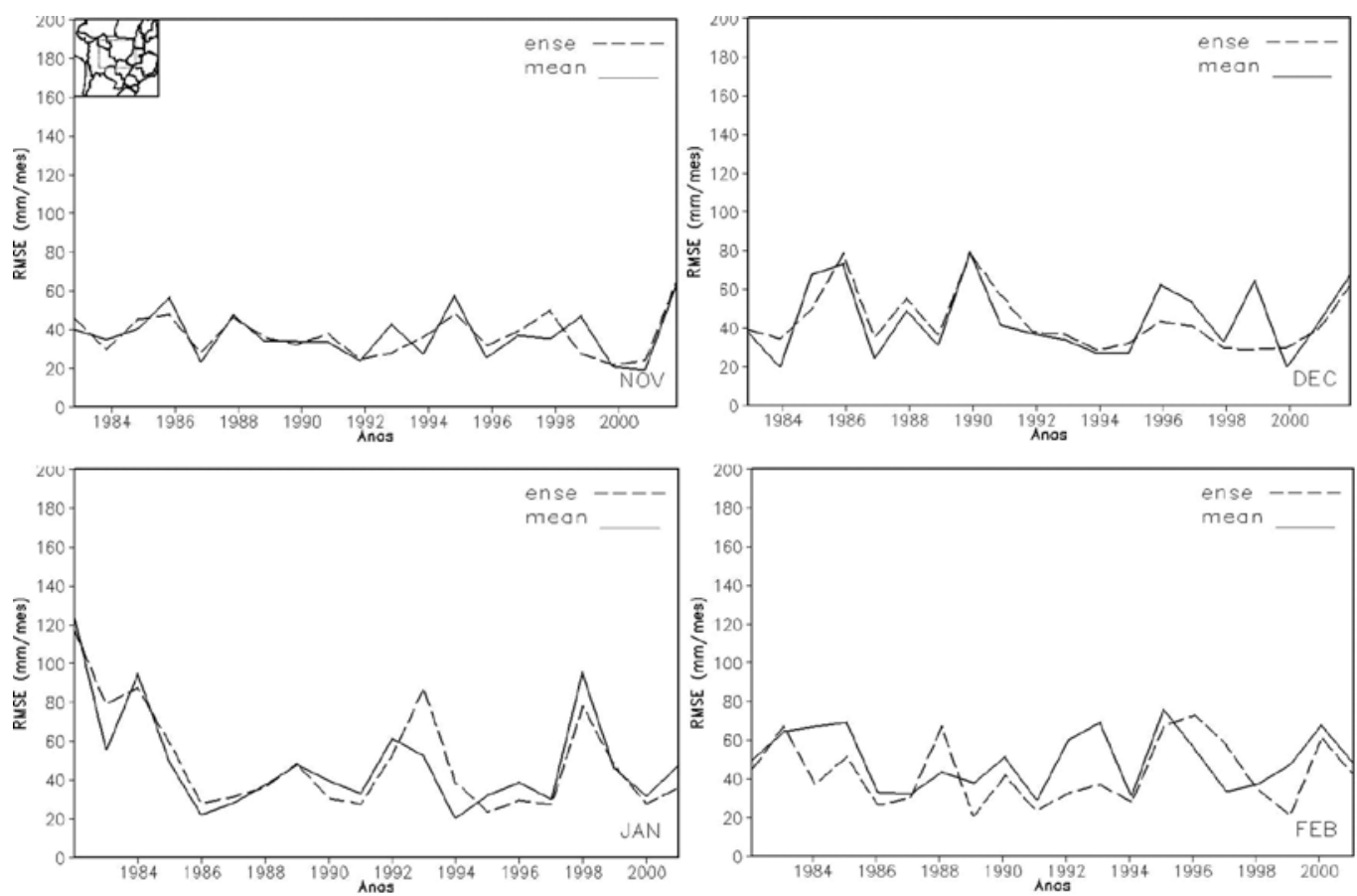

Figura 10 - Idem à Fig. 5, porém para a área $\mathrm{E}$ e para os meses de novembro a fevereiro
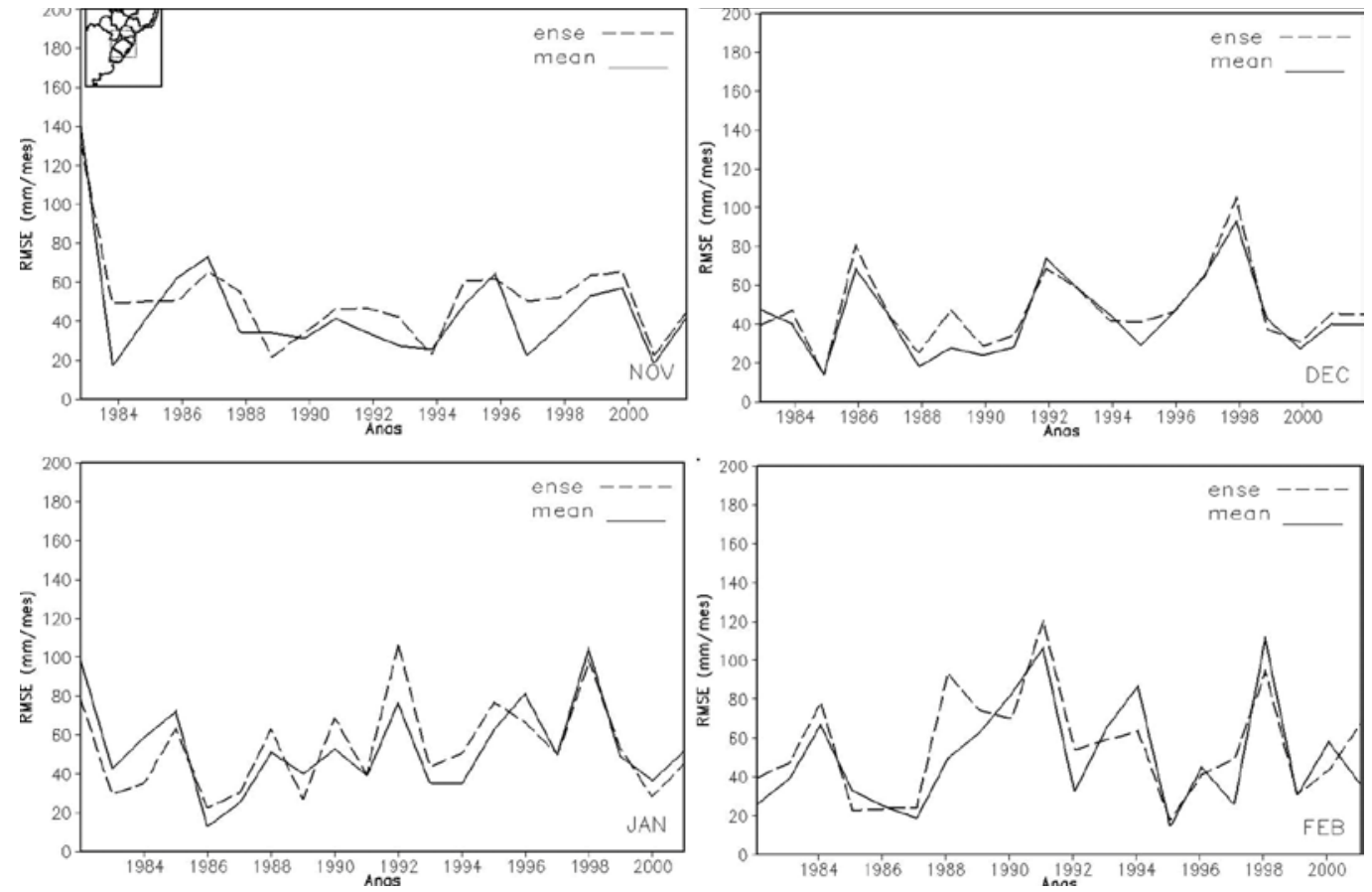

Figura 11 - Idem à Fig. 5, porém para a área $\mathrm{F}$ e para os meses de novembro a fevereiro 

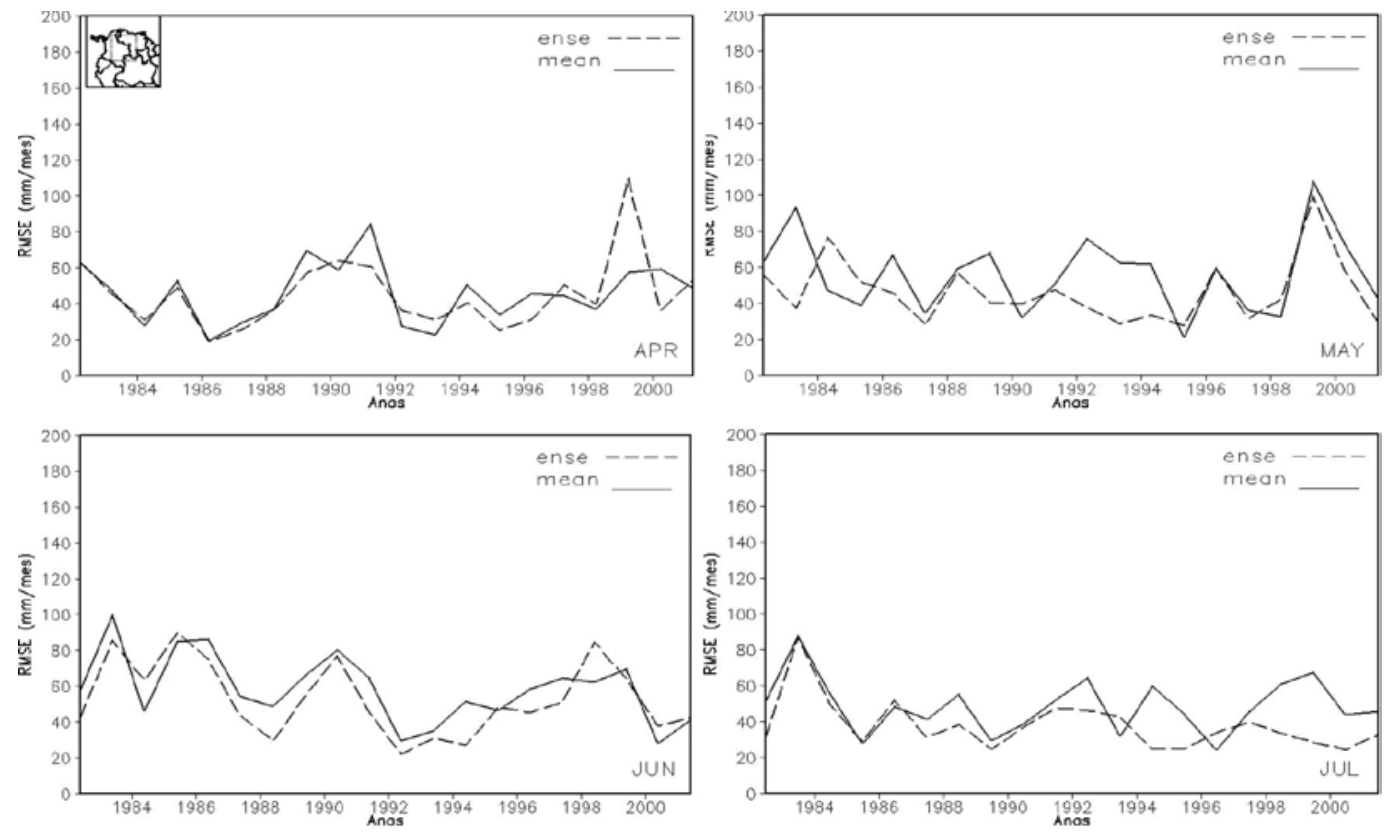

Figura 12 - Idem à Fig. 5, porém para a área $\mathrm{G}$ e para os meses de abril a julho

A região noroeste da América do Sul localiza-se no Hemisfério Norte e tem seu período chuvoso no final da estação de outono e início de verão deste hemisfério (aproximadamente de abril a julho). O ECCOCLIM apresenta bom desempenho em todos os meses do ano, com poucos casos em que os ENSEs se mantiveram acima dos correspondentes MEANs. A Figura 12 ilustra os gráficos de abril a junho.

A Figura 13 mostra os RMSE médios dos três diferentes esquemas utilizados na MEAN. O resultado mais marcante foi que o esquema GRELL apresentou os maiores valores de RMSE, sugerindo que, sua exclusão poderia trazer resultados mais satisfatórios. Isso pode ser mais bem ilustrado sobre a região da Amazônia Legal (áreas C, C1, E e parte da G) mostrados nas Figuras 13c, 13c1, 13d e 13g. Nas demais áreas, esse comportamento é menos evidente (Figuras 13d e 13f).

No Nordeste (Figuras 13a e 13b) os RMSEs com o esquema GRELL foram menores, apesar de que para alguns anos e para o setor sul os RMSEs foram superiores a 200 $\mathrm{mm} / \mathrm{mês}$.

Em geral, pode-se concluir que para a região da Amazônia Legal a parametrização utilizando o esquema GRELL pode não ser apropriada. Alonso (2006) analizou a Parametrização Convectiva de GRELL para duas distintas áreas, extratropical e tropical (Rio Grande do Sul e Amazônia, respectivamente), concluindo que no segundo caso não houve melhora na eficiência da simulação de precipitação total acumulada.

\section{CONCLUSÃO}

Foram apresentados os resultados do Esquema Estatístico de Combinação e Correção de Previsões Climáticas (ECCOCLIM), cujo desempenho foi avaliado comparando-se os erros médios quadráticos (RMSEs) das previsões com este esquema (ENSE) e com os da média aritmética dos modelos (MEAN). Comparando-se os RMSEs sazonais em cada ponto de grade, os erros do ECCOCLIM são menores do que os da MEAN ao longo do ano sobre o noroeste da América do Sul, e no verão sobre os Andes e na região da ZCAS. Para áreas selecionadas sobre a América do Sul, os ganhos com o ECCOCLIM são localizados em algumas regiões e variados ao longo dos anos. Melhorias consideráveis foram obtidas para o sul do Nordeste do Brasil nos meses de fevereiro e março e para o leste da Amazônia nos meses de maio a outubro, quando em geral os RMSEs da MEANs são maiores do que os RMSEs dos ENSEs. Por outro lado, nas áreas consideradas de baixa previsibilidade climática as melhorias com o uso do ECCOCLIM não são significativas embora para alguns meses o esquema forneça uma previsão ligeiramente melhor do que a média dos modelos.

A parametrização da convecção cumulus utilizando o esquema Grell pode não ser apropriada para a região Amazônica, pois maiores valores de RMSEs foram encontrados comparando-os com os encontrados nas parametrizações utilizando os esquemas RAS e KUO. 

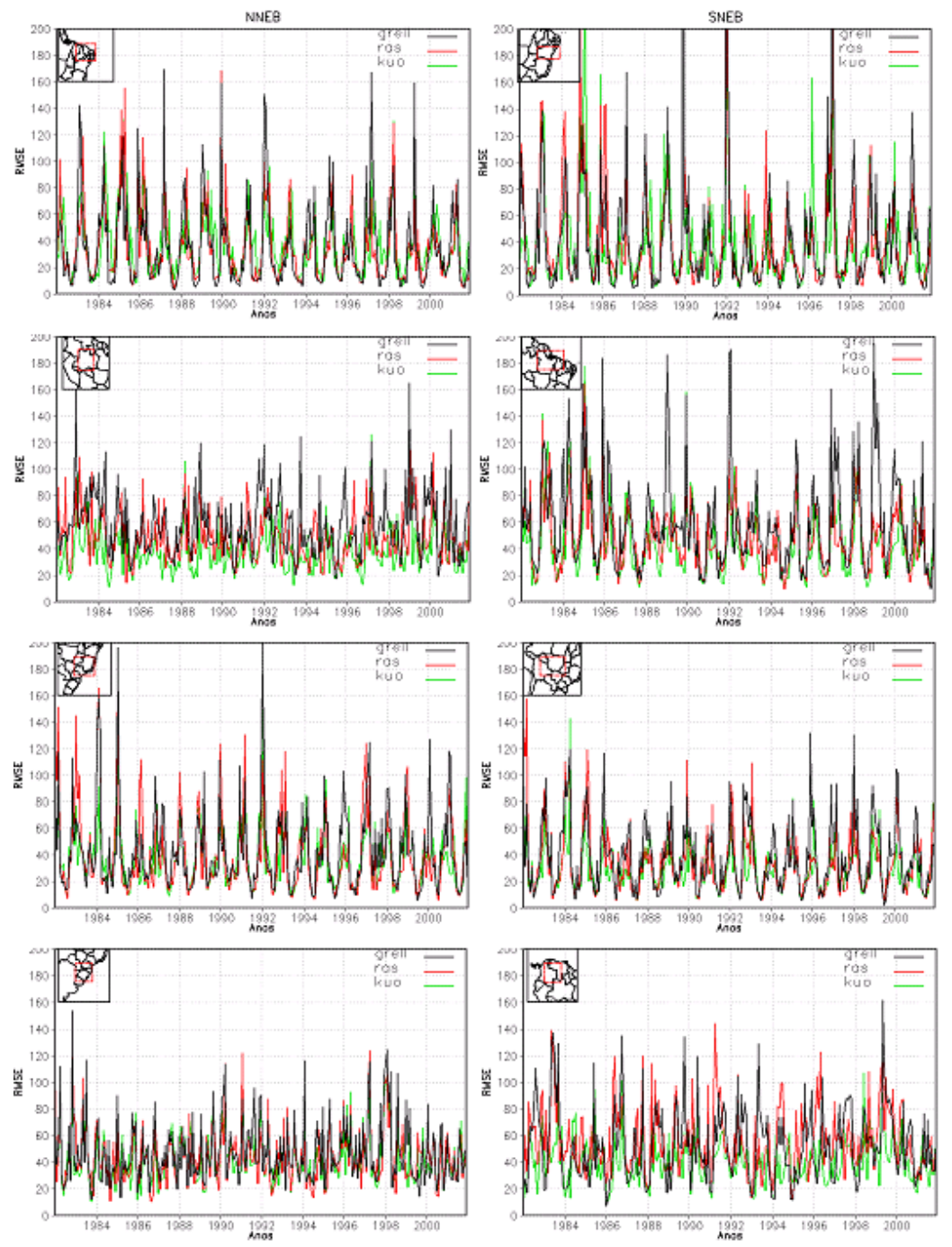

Figura 13 - RMSE médio nas áreas de A a G do modelo AGCM dos três diferentes esquemas, Grell ilustrado pela linha de cor preta , Ras na cor vermelha e Kuo, verde. Unidades expressas em mm/mês, período de janeiro 1982 a dezembro de 2001. A letra que representa as áreas das diferentes regiões representa também a letra da figura $(3 a-3 g)$.

Aparentemente, a dificuldade em se melhorar as previsões, via um esquema como o proposto deve ao fato de se usar um mesmo modelo, apenas com diferentes esquemas de parametrizações da convecção cumulus. O modelo do CPTEC, independente do esquema de parametrização da convecção cumulus, apresenta um RMSE para a maior parte da região de estudo da ordem de 60 a $100 \mathrm{~mm} / \mathrm{mês}$. Assim, para uma melhora efetiva da previsão de precipitação sobre a América do Sul seria necessário incluir no esquema outros modelos além do modelo do CPTEC.

\section{AGRADECIMENTOS}

O ECCOCLIM é um trabalho financiado pelo CPCLIM (472224/2004-2) Edital Universal/CNPq (19/2004) e pelo projeto PROTIM3/FINEP(0105091200). Esta é a contribuição 032006 do CPCLIM. Agradecemos Dirceu L. Herdies, José A. Aravéquia, Ronald B. Souza e Andréa Cardoso pelas sugestões fornecidas na fase inicial do trabalho. Agradecemos ao revisor anônimo por sua contribuição através de valiosas sugestões ao trabalho.

\section{REFERÊNCIAS BIBLIOGRÁFICAS}

Adler, R.; Huffman, G.; Chang, A.; Ferraro, R.; Xie, P.; Janowiak, J.; Rudolf, B.; Schneider, U; Curtis, S.; Bolvin, D.; Gruber, A.; Susskind, J.; Arkin, P. The version 2 global precipitation climatology project (GPCP) monthly precipitation analysis (1979-present). J. Hydrometeor., v. 4, p.1147-1167, 2003. 
Alonso, M. F. Estudo da influência do entranhamento de massa e do CAPMAX na simulação de precipitação pelo esquema convectivo de Grell para dois casos distintos de convecção. Anais do XIV CBMet. Florianópolis, 2006.

Cavalcanti, I. F. A. ; Marengo, J. A. ; Satyamurty, P. ; Nobre, C. A. ; Bonatti, J. P. ; Manzi, A. O. ; Pezzi, L. P. ; Castro, C. ; Sampaio, G. ; Camargo, H. . Global climatological features in a simulation using CPTEC/COLA AGCM. Journal of Climate, Boston, Ma, USA, v. 15, p. 2965-2988, 2002.

Coutinho, M. L.; Nascimento, M. G.; Coutinho, M. D. L.; Souza, E. P. Simulação de precipitação no Neb através de testes de Esquemas de Convecção do BRAMS. Anais do XIV CBMet. Florianópolis, 2006.

Danard, M. B.; Holl, M. M. e Clark, J. R. Fields by correlation assembly-A numerical analysis technique. Monthly Weather Review, v.96, p. 141-149, 1968.

Gneiting, T.; Raftery, A. E. Weather Forecasting with Ensemble Methods. Science, v. 310, n. 5746, p. 248-249, 2005.

Hoffmann, J. A. J. Climatic Atlas of South America - I. Ed. 1975 (OMM), 41 avenue Guiseppe - Motta, Genebra, 1975.

Kayano, M. and Andreoli R.. Relationships between rainfall anomalies over northeastern Brazil and the El Niño-Southern Oscillation. Journal of Geophysical Research.v.111, 2006.

Krishnamurti, T. N. ; Kishtawal, C. M.; LaRow, T. E. ; Bachiochi, D. R.; Zhang, Z.; Williford, C. E.; Gadgil, S.; Surendran, S. Improved Weather and Seasonal Climate Forecasts from Multimodel Superensemble. Science, v. 285, p. 1548-1550, 1999.

Krishnamurti, T. N.; Kishtawal, C. M.;.Zhang, Z. ; La Row, T.; Bachiochi, D., e Williford, E. C. Multimodel Ensembe Forecasts for Weather and Seasonal Forecasts. Journal of Climate, v.13, p. 4196-4216, 2000a.

Krishnamurti, T. N.; Kishtawal, C. M;.Shin, D. W. e Williford, C. E. Improving Tropical Precipitation Forecasts from Multianalysis Superensemble. Journal of Climate, v.13, p. 4217-4227, $2000 b$.

Krishnamurti, T. N.; Surendran, S.; Shin, D. W.; Correa-Torres R J.; Vijaya Kumar, T. S. V., Williford. E., Kummerow, C, Adler, R. F., Simpson, J., Kakar, R., Olson, W. S., and Turk, R.F. Real-Time Multianalysis-Multimodel Superensemble Forecasts of Precipitation Using TRMM and SSM/I Products. Monthly Weather Review, v.129, p. 2861-2883, 2001.
Lorenz, E. N. Deterministic non-periodic flow. J. Atmos. Sci., v. 20, p. 130-141, 1963.

Marengo, J. Interannual variability of deep convection in the tropical South American sector as deduced from ISCCP C2 data. International Journal of Climatology, v.15, n.9, p. 995-1010, 1995.

Moura, A. D.; Shukla, J. On the dynamics of droughts in northeast of bra-zil: Observations, theory and numerical experiments with general circulation model. Journal of the Atmospheric Sciences, v. 38, p. 2653-2675, 1981.

Pezzi, L. P.; Cavalcanti, I. The relative importance of ENSO and tropical Atlantic sea surface temperature anomalies for seasonal precipitation over South America: A numerical study. Climate Dynamics, v.17, p. 205-212, 2001.

Pezzi, L. P.; Cavalcanti, I., F., A.; Mendonça, A., M. A sensitivity study using two different convection schemes over South America. Submetido a Revista Brasileira de Meteorologia, 2006a.

Pezzi, L. P.; Bezerra, A. C.; Kayano, M; Tomita, S. S. Esquema Estatístico de Combinação e Correção de Previsões Climáticas (ECCOCLIM) sobre o Brasil. Anais do XIV CBMet. Florianópolis, 2006b.

Rao, V. B. e Hada, K. Characteristics of Rainfall over Brazil: Annual Variations and Connections with the Southern Oscillation, Theoretical and Applied Climatology, v. 42, p. 81- 91, 1990.

Ropelewski, C.F.; Halpert, M. S. Global and regional scale precipitation patterns associated with the El Niño/Southern Oscillation, Mon. Wea. Rev., v. 115, p. 1606-1626, 1987.

Ropelewski, C.F., and M.S. Halpert, Precipitation patterns associated with the high index phase of the Southern Oscillation, J. Climate, 2, 268-284, 1989.

Silva, R. R.; Dias, P. S.; Gandu, A.; Moreira D. S. Impactos da temperatura da superfície do mar no Ciclone catarina. Site: http://ciram.epagri.rct-sc.br:8080/cms/meteoro/noticias/ furacao_catarina_artigos.jsp. Acessado em 25/10/2006 às 9:24. 2004.

Thompson, P. D. How to improve accuracy by combining independent forecasts. Monthly Weather Review, v.105, p. 228-229, 1977. 